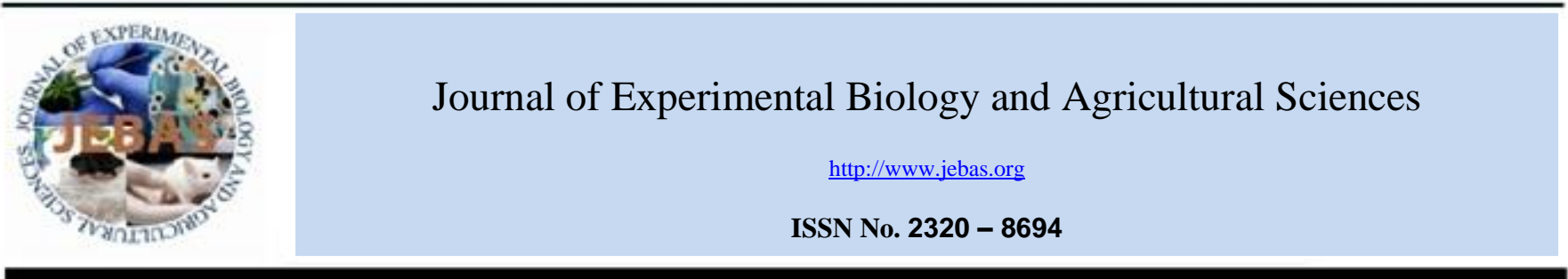

\title{
ANALYSIS OF THE TECHNICAL EFFICIENCY, PURE AND SCALE EFFICIENCY OF RAINED CEREAL FARMS: CASE OF THE UPPER SEMI-ARID
}

\author{
Abdelhafidh hassen ${ }^{1 *}$, Ben Brahim Marwa ${ }^{2}$, Abed Hanen ${ }^{3}$, Mekki Amira ${ }^{1}$ \\ ${ }^{1}$ Ecole supérieure d'Agriculture de Mograne, Université de Carthage. Tunisia \\ ${ }^{2}$ Institut National Agronomique de Tunis, Université de Carthage. Tunisia \\ ${ }^{3}$ Institut National des Recherches Agronomiques de Tunis, Université de Carthage. Tunisia
}

Received - April 30, 2017; Revision - May 20, 2017; Accepted - May 27, 2017

Available Online - August 31, 2017

DOI: http://dx.doi.org/10.18006/2017.5(Spl-1-SAFSAW).S116.S125

KEYWORDS
Technical efficiency
Durum wheat
DEA
food security
Tunisia

\begin{abstract}
Tunisia is being faced with severe challenges in increasing wheat production in order to enhance the self-sufficiency ratio for wheat production. Using Data Envelopment Analysis (DEA), this paper provides an evaluation of the performance of a sample of rainy Durum Wheat producers in the region of Zaghouan (center of Tunisia) in upper semi-arid by means of overall technical, pure technical and scale efficiency and the performance of the average production unit. The factors which influence the efficiency scores in rainy wheat production, have been also determined using a Tobit model. Data were collected from 105 farms in 2015-2016. Results of study revealed that technical rather than scale inefficiency is the main source of productive inefficiency. The average overall technical, pure technical and scale efficiencies are $58 \%, 73 \%$ and $81 \%$ respectively, indicating that production efficiency can be improved by $42 \%$ without having to increase their input's utilization. Most farms, $74.3 \%$ operate in increasing return to scale while 12.4 of them have decreasing returns to scale and only $13.3 \%$ are scale efficient. Hence, the farmers need some adjustments in their use of production inputs in order to operate on the optimal level. Results of Tobit model analysis showed a positive effect of the education level of farmers, farm size, main occupation, and technical package set including variety, nitrogen use, herbicides, pesticides and previous crops which are important policy variables and determinants of efficiency which can be integrated into the agricultural policy in Tunisia in order to raise the current level of productivity, food security and hence the sustainability development.
\end{abstract}

* Corresponding author

E-mail: Abdelhafidhhassen@yahoo.fr (Abdelhafidh hassen)

Peer review under responsibility of Journal of Experimental Biology and Agricultural Sciences.

Production and Hosting by Horizon Publisher India [HPI] (http://www.horizonpublisherindia.in/).

All rights reserved.
All the article published by Journal of Experimental Biology and Agricultural Sciences is licensed under a Creative Commons Attribution-NonCommercial 4.0 International License Based on a work at www.jebas.org.

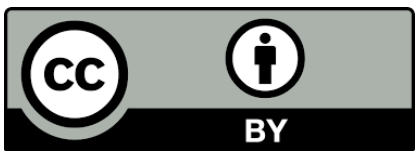




\section{Introduction}

Cereals constitute an important niche in the Tunisian agricultural economy; all the more so, it is a crossroads sector, with multiple implications for the whole national economy. Indeed, the cereal economy affects the country's food security, the local production, policies for industrial stimulation, both upstream and downstream development of cereal production, the foreign trade, the country's rural population, the balance of public finances and, finally, the allocation of investment resources. Since Tunisia has achieved independence, cereal policies have been mainly implemented in terms of prices, technology diffusion, credit and investment support.

The aim of these policies was to increase cereal production and improve the level of food security. Nowadays, cereals are among the main crops in Tunisia. The sector plays an undeniable social and economic role. It provides major staple food commodities for nearly all communities and households. About one third of the country's arable lands have been devoted to cereal production in the last decade. From 2003 to 2015 the cereals areas varied from 1.146 million hectares in 2004 to 1.643 in 2013 (5 million hectares, and $2 / 3$ of farms). In this period, about 50 percent of the production has been in durum wheat, 9 percent in bread wheat, and 38 percent in barley. The sector supplied the country with 3.9 million tons in 2015 ; let $13 \%$ of the total agricultural production. The average production of the last 10 years is around 1.7 million tons with a variation of 0.73 million tons (Chemak et al., 2010; Chebil et al., 2015).

Wheat is grown in different localities of Tunisia; but the humid and semi-arid Northern regions are the most suitable grounds for this crop. Average wheat yields (1.4 tons/ha) are lower compared to the world average (3.6 tons tons/ha) (Laajimi et al., 2013; Chebil et al, 2015). Further, same authors revealed that, these low yields can be explained by many production and environmental factors, including low and uncertain rainfall with frequent droughts, common diseases such as septoria, root rots and insects, limited availability of inputs and high production costs, in addition to the limited adoption of improved production packages (Chebil et al., 2015).

Tunisia is being faced severe challenges in increasing wheat production in order to enhance the self-sufficiency ratio for wheat production. During the last three decades, durum wheat imports in Tunisia have increased by $5.1 \%$ (FAO, 2014). Hence, the wheat sector is characterized by a large deficit between domestic needs and production. This gap is growing because of many factors, including disproportionate urbanization and higher living standards, rural exodus, population growth, limited land and water resources to extend the wheat areas, and the low increases in productivity rates. This rising gap has considerably led to greater reliance on imports. During the last decades, almost half of wheat consumption needs was imported annually. As wheat prices are increasing in the international market, the cost of wheat importation is becoming more expensive too. Public subsidies to the cereals 'sector have been higher especially during the socalled international "food crisis" (Laajimi et al., 2013). Thus, enhancing wheat productivity growth in Tunisia became a necessity for increasing the wheat self-sufficiency ratio (Chebil et al., 2014).

Productivity is a crucial aspect of economic performance; it affects both producers' and consumers' welfare. Durum Wheat productivity in the country remains very low compared to its potential. The current average yield per hectare does not exceed 1.4Tons (Ministry of Agriculture and Water Resources, 2010). This low productivity combined to strong climate variability make importation yearly required in order to meet the domestic demand of approximately 3.6 million tons (ONAGRI, 2015). This situation was worsened by the latest increases of world food prices. Improvement of the cereal productivity in Tunisia became an obligation for policy makers who need to reduce the import bill related to this commodity. One of the main reasons for the current low cereals productivity in Tunisia is the inability of farmers to fully exploit the available technologies, resulting in lower production efficiencies. Although many solutions were proposed for yields improvements, wheat yield in semi arid areas is still being stabilized around 1.6 tons/ha.

Under these conditions, the level of technical efficiency of farms can be an important factor in improving both farm yields and profitability. In fact, technical efficiency determines the level of profitability and profit achieved and the potential gain in productivity. In addition, many cereal farms have been able to realize productivity gains through the efficient use of productive technologies during several medium-rainfall campaigns.

The aim of this study was to measure the potential productivity gains by Tunisian cereal farms by estimating technical efficiency for a sample of wheat producers in the region of Zaghouan (central semi-arid Tunisia). The second objective was to assess the effect of several technical, economic, and demographic farmers' attributes on the estimated production efficiencies. The DEA approach has been used to measure the technical efficiencies.

\section{Theoretical Framework}

\subsection{Production Functions and Efficiency: Some Theoretical Issues}

This section discusses production functions and some related concepts which form the basis of measuring the farm efficiency. We explain the basic concepts of technical, allocative and economic efficiency. The measurement of efficiency was first proposed by Farrell (1957). The failure to produce the maximum output from a given input mix at minimum cost results in inefficiency. Inefficiency is explained by, inter alia, restricted access to technology, a lack of knowledge, restricted access to extension services, inappropriate scale of production and sub- 
optimal allocation of resources. The efficiency of a farm consists of two components: technical and allocative efficiency. Technical efficiency concerns the ability of a farm to produce maximum output from a given set of inputs using existing technology.

\subsubsection{Production Functions}

In microeconomic theory, the production function explains the technical or physical relationship between output and inputs. Specifically it shows the maximum output obtainable from a given set of inputs. Inputs are rates of resource use and output is the rate of production over a specific time period. Let $\left(\mathrm{x}_{1}, \mathrm{x}_{2} \ldots \mathrm{x}_{\mathrm{n}}\right)$ denote the inputs used in the production of output $\mathrm{y}$; the production function can be written as:

$y_{i}=f\left(x_{1}, x_{2}, \ldots \ldots . . x_{n}\right)$

The production function is the boundary of a production set. Consider the Figure 1 where, for simplicity, one input $x$ is used to produce a single output $\mathrm{y}$. The production set, $\mathrm{Q}$, denotes the technically feasible production set $(\mathrm{y}, \mathrm{x})$, i.e., $\mathrm{Q}=(\mathrm{y}, \mathrm{x})$. The region under the curve $\mathrm{y}=\mathrm{f}(\mathrm{x})$ in the Figure 1 represents the production set.

The production combinations which maximize $\mathrm{y}$ for given $\mathrm{x}$ or minimize $\mathrm{x}$ for given $\mathrm{y}$ are technically efficient combinations and constitute the boundary to the production set $\mathrm{Q}=(\mathrm{y}, \mathrm{x})$. Thus the production function $y=f(x)$ is the set of technically efficient combinations, and all technically inefficient combinations belonging to the interior of the production set.

An isoquant or production indifference curve is defined as the locus of all the technical efficient combinations of inputs which produce the same output. It shows the rate at which inputs are substituted in production holding output constant. For simplicity consider the two variable production function:

$y=f\left(x_{1}, x_{2}\right)$

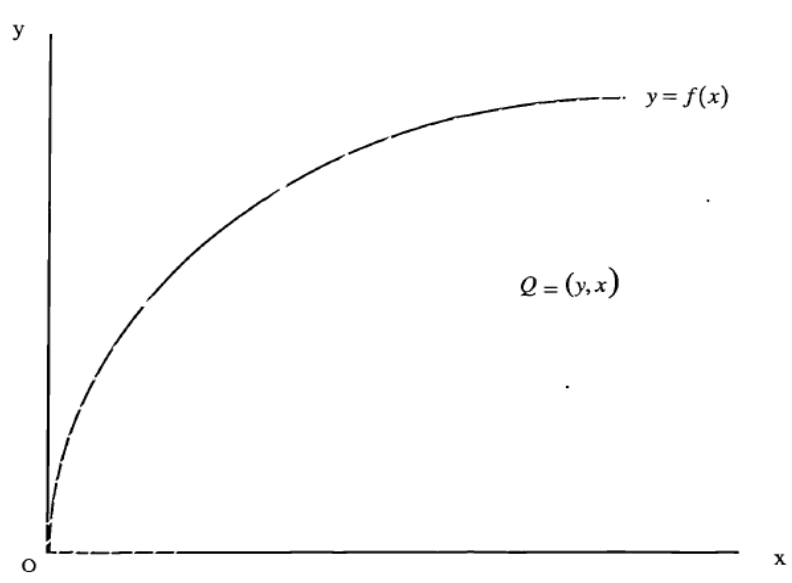

Figure 2 Production Function
The equation of an isoquant is obtained by the production function (2) when output is held constant at say $y_{0}$ :

$\mathrm{y}_{0}=\mathrm{f}\left(\mathrm{x}_{1}, \mathrm{x}_{2}\right)$

This represents the isoquant which displays all combinations of inputs that can be used to produce output $y$. The slope of the isoquant at any point is derived by differentiating (3) implicitly with respect to one of the inputs, say $x_{1}$. This yields

$\frac{\mathrm{dx}_{2}}{\mathrm{dx}_{1}}=\frac{\mathrm{f}_{1}}{\mathrm{f}_{2}}$

The negative of the slope of an isoquant is the marginal rate of technical substitution (MRTS) which measures the rate at which inputs can be substituted, keeping output constant.

The isocost line shows the rate at which inputs are exchanged in the market (their relative prices). It is the locus of all combinations of inputs that can be purchased with a given cost outlay, that is, the isocost line is the locus of input combinations that entails the same total $\operatorname{cost} \mathrm{C}_{0}$ :

$\mathrm{C}_{0}=\mathrm{P}_{1} \mathrm{x}_{1}+\mathrm{P}_{2} \mathrm{x}_{2}$

Where $\mathrm{P}_{1}$ and $\mathrm{P}_{2}$ are the input prices of $\mathrm{x}_{1}$ and $\mathrm{x}_{2}$ and its slope is found by differentiating the isocost line:

$\frac{\partial \mathrm{x}_{2}}{\partial \mathrm{x}_{1}}=-\frac{\mathrm{P}_{1}}{\mathrm{P}_{2}}$

Which is the negative of the ratio of the input prices.

\subsubsection{Choice of Cost Minimizing Input Mix}

We explain the problem of finding the least-cost input combination that the farm chooses for the production of a specified level of output $y_{0}$. The choice of a cost-minimizing input combination deals with the issue of how cost can be minimized? We assume that output and the price of the inputs are given. Cost minimization requires the tangency of the given isoquant with the lowest possible isocost line.

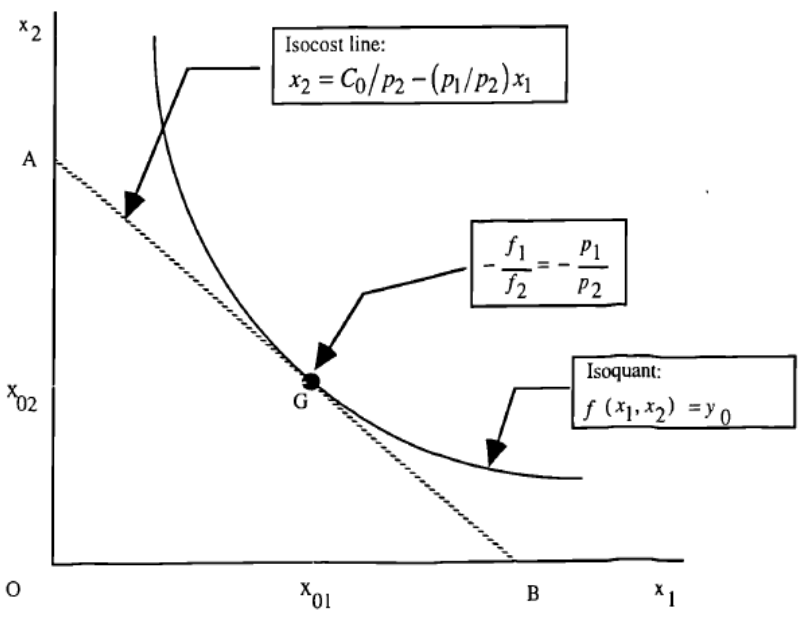

Figure 1 Isoquant, Isocost line and Cost Minimization 
The farm minimizes its costs by using input combination $\left(\mathrm{x}_{01}, \mathrm{x}_{02}\right)$ determined by the tangency point of the given isoquant $\mathrm{y}_{0}$ with the isocost line $\mathrm{AB}$. The cost-minimizing input combination is obtained at a point where the slopes of the isoquant and the isocost line are equal.

$\frac{f_{1}}{f_{2}}=\frac{P_{1}}{P_{2}}$

Obtaining the cost-minimizing input vector ensures allocative efficiency.

Equation (7) provides the first-order conditions for cost minimization.

\subsection{Measures of Technical Efficiency}

\subsubsection{Defining Efficiency}

The term "efficiency" implies the success with which a farm best utilizes its available resources to produce maximum levels of potential outputs (Dinc et al., 1998). A farm is efficient if and only if it is not possible to increase output (decrease inputs) without more inputs use (without decreasing output) (Cooper et al., 1995). Failure to obtain this potential maximum output results in inefficiency.

The concept of productive efficiency was first introduced by (Farrell, 1957). A farm is technically efficient if it produces a maximum output, given the amount of inputs and technology. Thus the production frontier is associated with the maximum obtainable level of output, given a level of inputs, or the minimum level of inputs required to produce a given output. Technical inefficiency is attributed to a failure of the farm to produce the frontier level of output, given the quantities of inputs (Kumbhakar, 1994).

In Figure 3, it is assumed that there are two inputs $\left(\mathrm{X}_{1}\right.$ and $\left.\mathrm{X}_{2}\right)$ used by a firm to produce a single output (Y) with assumption of

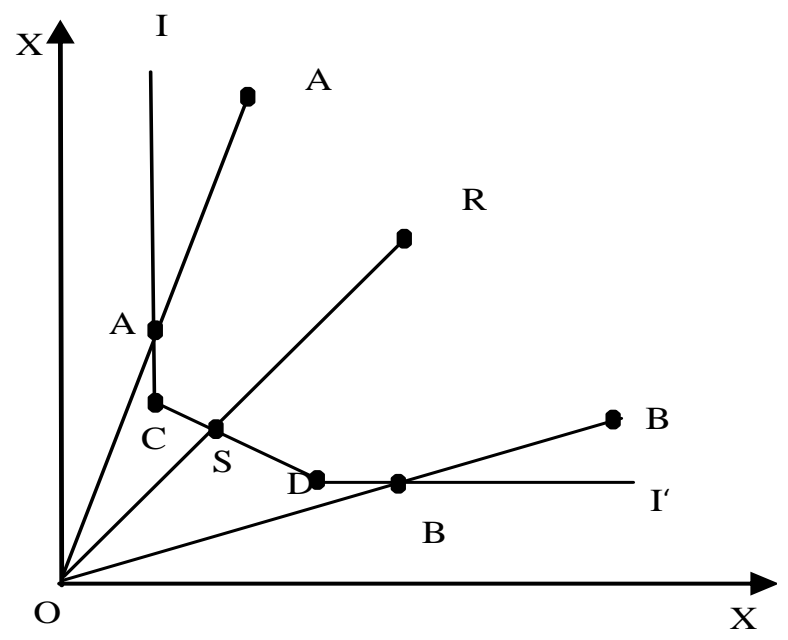

Figure 3 Technical Efficiency, Radial adiustment, and slack identified constant returns to scale. The II' curve represents the isoquant of fully efficient firms, and could be used to measure TE. If the firm employs amount inputs at point $\mathrm{R}$ to produce a unit of output, the technical inefficiency of that firm could be measured by the distance RS. This is the proportion by which the use of inputs could be reduced without a decrease in output. This is expressed in percentage terms by the ratio SR/OR, which stands for the percentage by which all inputs need to be reduced to gain production which is technically efficient. The TE of a firm is measured by the ratio: $\mathrm{TE}=\mathrm{OS} / \mathrm{OR}$. If a firm has TE equal to 1 , it is technically efficient. The firm is technically inefficient if its TE value is less than 1 . If the TE is equal to 1 , the firm produces with full technical efficiency. At point $S$ the firm could gain full technical efficiency because point $S$ lies in the efficient production indifference curve.

The efficiency measures proposed by Farrell assume a known production function for the fully efficient DMU. The production function of a DMU is generally unknown in practice, and relative efficiencies must be measured from the sample data available. Two approaches are used to estimate relative efficiency indices: the parametric or stochastic frontier production approach (SFA) and the nonparametric or data envelopment analysis approach (DEA) (Coelli, 1995). The SFA assumes a functional relationship between outputs and inputs and uses statistical techniques to estimate parameters for the function. It incorporates an error composed of two additive components: a symmetric component that accounts for statistical noise associated with data measurement errors and a non-negative component that measures inefficiency in production (Coelli, 1995). The stochastic model specification of SFA also allows for hypothesis testing. The disadvantage of SFA is that it imposes specific assumptions on both the functional form of the frontier and the distribution of the error term. In contrast, DEA uses linear programming methods to construct a piecewise frontier of the data. Because it is nonparametric, DEA does not require any assumptions to be made about functional form or distribution type. It is thus less sensitive to misspecification relative to SFA. However, the deterministic nature of DEA means all deviations from the frontier are attributed to inefficiency. It is therefore subject to statistical noises resulting from data measurement errors (Coelli, 1995).

The choice of which method to use is unclear (Olesen et al., 1996). A small number of studies make side by side comparisons of the two methods (Sharma et al., 1997; Sharma et al., 1999; Wadud \& White, 2000; Wadud, 2003; Theodoridis \& Psychoudakis, 2008; Theodoridis \& Anwar, 2011), but none of these studies make any conclusions about which method is superior. These studies typically find quantitative differences in efficiency scores between the two methods, but the ordinal efficiency rankings among DMUs tend to be very similar for both methods. Therefore, the choice of which method to use appears to be arbitrary, as is pointed out by Dhungana et al. (2004). We chose the DEA approach in this study, since it imposes no a priori 
parametric restriction on the underlying technology (Chavas \& Aliber, 1993; Fletschner \& Zepeda, 2002; Wu \& Prato, 2006).

\section{Methodology}

3.1 Measurement of Technical, Pure Technical, and Scale Efficiencies: CCR and BCC DEA models

As noted above, we intend to apply the technique of DEA for computing the measures of technical, pure technical, and scale efficiencies for individual wheat producers. In DEA, technical efficiency (TE) can be viewed from two perspectives. First, input oriented TE focuses on the possibility of reducing inputs to produce given output levels. Second, output-oriented TE considers the possible expansion in outputs for a given set of input quantities. A measure of TE for a DMU can be defined as:

$\theta^{\text {output }}=$ actual output $/$ Maximum possible output

in output-oriented context,

or $\theta^{\text {input }}=$ Minimum input possible $/$ Actual input

in input-oriented context.

To quantify a measure of TE, we need to find out the divergence between actual production and production on the boundary of the feasible production set. This set summarizes all technological possibilities of transforming inputs into outputs that are available to the organization. A DMU is technically inefficient if production occurs within the interior of this production set. A measure of scale efficiency (SE) can be obtained by comparing TE measures derived under the assumptions of constant returns-to-scale (CRS) and variable returns-to-scale (VRS). As noted above, the TE measure corresponding to CRS assumption represents overall technical efficiency (OTE) which measures inefficiencies due to the input/output configuration and as well as the size of operations.

The efficiency measure corresponding to VRS assumption represents pure technical efficiency (PTE) which measures inefficiencies due to only managerial underperformance. The relationship $\mathrm{SE}=\mathrm{OTE} / \mathrm{PTE}$ provides a measure of scale efficiency

\subsubsection{Overall Technical efficiency}

Under the non-parametric approach (DEA), to estimate the production frontier, we consider the "input oriented" model, according to Coelli (1996) and we have in the model presented here : $\mathrm{n}$ farms $(\mathrm{i}=1, \ldots \ldots \mathrm{n})$, each producing $\mathrm{M}$ outputs $\mathrm{y}_{\mathrm{mn}}$ $(\mathrm{m}=1, \ldots \mathrm{M})$ by using $\mathrm{K}$ different inputs $\mathrm{x}_{\mathrm{kn}}(\mathrm{k}=1, \ldots . \mathrm{K})$, each farm becoming the reference unit. For the ith firm we have vectors $x_{i}$ $\left(\mathrm{K}^{*} 1\right)$ and yi $\left(\mathrm{M}^{*} 1\right)$. For the entire data set, therefore, we have a $\mathrm{K} * \mathrm{~N}$ input matrix $\mathrm{X}$ and $\mathrm{M} * \mathrm{~N}$ output matrix $\mathrm{Y}$. The technical efficiency (TE) measure is obtained by solving The CCR model which was initially proposed by Charnes et al. (1978). The CCR model is indicated in Eq. (8): $\min _{\theta, \lambda} \theta_{\mathrm{i}}$

$\mathrm{Sc}$

$-\mathrm{y}_{\mathrm{i}}+\mathrm{Y} \lambda \geq 0$

$\theta \mathrm{x}_{\mathrm{i}}-\mathrm{X} \lambda \geq 0$

$\lambda \geq 0$

Where $\theta_{\mathrm{i}}$ is a variable representing the efficiency of the Reference Farm $i$ and hence the percentage of reduction to which each input must be subjected to reach the production frontier. $\lambda$ is a vector of $\left(\mathrm{k}^{*} 1\right)$ elements representing the influence of each farm in determining the efficiency of the ith farm.

\subsubsection{Pure technical efficiency and Scale efficiency}

Pure technical efficiency is technical efficiency of BCC model. The BCC model was initially proposed by Banker et al. (1984). The input-oriented BCC model evaluates the efficiency of DMUj by solving the following program:

$\min _{\theta, \lambda} \theta_{\mathrm{i}}$

$\mathrm{Sc}$

$-\mathrm{y}_{\mathrm{i}}+\mathrm{Y} \lambda \geq 0$

$\theta \mathrm{x}_{\mathrm{i}}-\mathrm{X} \lambda \geq 0$

$\sum_{i=1}^{N} \lambda_{i}=1$

$\lambda \mathrm{i} \geq 0$

Based on the CCR and BCC scores, scale efficiency defined by (Cooper et al., 2006):

$\mathrm{SE}=\frac{\mathrm{TE}_{\mathrm{CCR}}}{\mathrm{TE}_{\mathrm{BCC}}}$

In other words, decomposition of Eq. (10) can be defined by:

$\mathrm{TE}_{\mathrm{CCR}}=\mathrm{SE} \cdot \mathrm{TE}_{\mathrm{BCC}}$

If the scale efficiency is less than 1, the DMU will be operating either at decreasing returns to scale (DRS) if a proportional increase of all input levels produces a less-than-proportional increase in output levels or increasing return to scale (IRS) at the converse case. This implies that resources may be transferred from DMUs operating at DRS to scale to those operating at IRS to increase average productivity at both sets of DMUs (Boussofiane et al., 1992).

\subsubsection{Slack and radial adjustments}

DEA identifies the most efficient point on the frontier as a target for those inefficient. For the ith DMU, the distance from an inefficient point, where it is located, to the projected point on the frontier by radial adjusting the level of inputs, $\left(1-\theta_{\mathrm{i}}\right) \mathrm{x}_{\mathrm{i}}$, is called "radial adjustment". Moreover, the mostly seen piecewise-linear form of the non-parametric frontier causes the second stage to 
shift from the projected point to a point at the practical minimum level of the inputs on the frontier. The distance of shifting along with the frontier in between is called "slack". How a point with a practical minimum level for inputs on the frontier can be identified in DEA is illustrated in Figure 2 with a case of one output and two inputs. The maximum level y output by the DMUs located on the frontier is normalized to unity and generated from the inputs which are also normalized by dividing $\mathrm{y}$. Point $\mathrm{R}$ is the actual input set and point $S$ is the projected point on the frontier for DMU $\mathrm{R}$ as the target in order to improve its efficiency accordingly by reducing the radial adjustment RS .

Yet, as aforementioned, the practical frontier is a piecewise linear format that requires the second-stage adjustment to determine a practical minimum point for inputs. In Figure 2, point B' is the projected point on the frontier for another DMU B as the target to reach by reducing the radial adjustment BB'. Therefore the input level at point B' could be further reduced to the input level at point $\mathrm{D}$ while maintaining at the same time the same output level. The amount DB' that shall further be adjusted for the input level at point B' along with the frontier is called 'slack'.

The summation amount of slack (DB') and radial adjustment (BB') for inputs is called the amount of total adjustments (DB), meaning that it is the total amount for inputs which should be adjusted by a DMU so as to reach its optimal production efficiency. The adjustments require both a promotion of technology level and an improvement in the production process so that OTE is optimized. The amount of total adjustments therefore decreases and the output level is maximized so that the DMU operates at the frontier position of production efficiency. The practical minimum input level is called the target input level for a DMU. The summation of slack and radial adjustment for input is the total adjustment amount, meaning the total amount needs to adjust so as to reach a 'target' input while keeping output unchanged. For an input, this summation provides a 'Input reduction target' (IRT) and for any input $\mathrm{X}$ the formula as defined by $\mathrm{Hu}$ et al. (2006) is as follows:

$\operatorname{IRT}(X)=$ Radial adjustment of input $X+$ Slack of input $X$.

Then an inefficient DMU can reduce the IRT without reducing its growth and so it can improve its efficiency. The CRS model of DEA suggests the slack and radical adjustment of the individual input and the amount of target input can be calculated accordingly. The 'total adjustment amount' is then obtained from the gap between actual input amount and target input amount.

The IRT computed by DEA shows a target amount of input to be reduced in a DMU or in a region to reach the optimal production efficiency at the frontier and therefore a simple index named the Input adjustment target ratio (IATR) is constructed as a ratio format of IRT to measure the ratio of IRT to the amount of total water use in the region ( $\mathrm{Hu}$ et al., 2006). The IATR index is constructed below:
Input Adjustment Target Ratio (IATR) $=\frac{\text { Input Reduction Target }}{\text { Actual Input }}$

The IATR reflects what ratio of Input use is able to decrease without impacting the regional economic output level.

\subsection{Tobit Model}

Present study uses the Tobit regression to analyse the role of farm attributes in explaining TE. This approach has been used widely in efficiency literature (Speelman et al., 2008; Naceur et al., 2010; Chebil et al., 2015). In fact, the values of the dependent variable lie in the interval (0-1). The censored Tobit model can be then used to get consistent estimation. The Tobit regression used in our study is specified as follows:

$$
\theta_{\mathrm{i}}=\left\{\begin{array}{l}
\theta_{\mathrm{i}}^{*} \text { if } 0<\theta_{\mathrm{i}}^{*}<1 \\
0 \text { if } \theta_{\mathrm{i}}^{*} \leq 0 \\
1 \text { if } \theta_{\mathrm{i}}^{*} \geq 1
\end{array}\right.
$$

Where $\theta_{\mathrm{i}}$ are technical efficiency scores used as dependant variables. $\theta^{*}$ : is the value of an artificial variable (unobservable) that is related to explanatory variables $\left(\mathrm{X}_{\mathrm{i}}\right)$ as the following relationship:

$\theta_{\mathrm{i}}^{*}=\mathrm{x}_{\mathrm{i}} \beta^{*}+\varepsilon_{\mathrm{i}}$

Where: $\varepsilon i$ error term and $\beta$ are parameters to be estimated.

The estimation of the Tobit model is based on maximum likelihood procedures. For Tobit estimates to be consistent, it is necessary that residuals are normally distributed (Holden, 2004).

\subsection{Data and empirical procedures}

\subsubsection{Study area}

The data used in the current study is about the production structure of 105 rained wheat farms located in the governorate of Zaghouan. This semi-arid region is located in Central Tunisia and has an annual average rainfall of about $400 \mathrm{~mm}$. The landed area is about $185000 \mathrm{Ha}$. The main crops cultivated in the area are: wheat, vegetables, fodder and olives. The number of farmers is around 11140 . Total cereals area is about 80000 ha. The durum wheat yield is around 1.5 ton/ha. Farmers were randomly selected. Data used is collected in 2015 by face to face interviews with cereal-growing farmers.

\subsubsection{Variables in the empirical analysis}

One output (production in qx) and seven inputs (wheat cropped land in ha, seeds in qx, Nitrogen in qx, Di Ammonitrate Phosphoric (DAP) in qx, Pesticides expenses in TDN, Machinery in hour and Labour in days.), were used in the DEA models. statistics related to inputs use, outputs, and farm specific variables are presented in Table 1. 
Table 1 Summary statistics of the variables used in the analysis of efficiency

\begin{tabular}{|c|c|c|c|c|c|}
\hline \multicolumn{2}{|l|}{ Variables } & \multirow{2}{*}{$\begin{array}{c}\text { Mean } \\
1335\end{array}$} & \multirow{2}{*}{$\begin{array}{l}\text { S.D } \\
2620\end{array}$} & \multirow{2}{*}{$\begin{array}{c}\text { MIN } \\
12\end{array}$} & \multirow{2}{*}{$\begin{array}{c}\text { Max } \\
20850\end{array}$} \\
\hline Output & Output quantity(qx) & & & & \\
\hline \multirow[t]{7}{*}{ Inputs } & Wheat Area(ha) & 72 & 108 & 2 & 700 \\
\hline & Seeds (qx) & 123 & 190 & 4 & 1300 \\
\hline & Nitrogen (qx) & 122 & 216 & 0 & 1700 \\
\hline & DAP fertilizer(qx) & 76 & 113 & 0 & 700 \\
\hline & Pesticides (TND) & 4810 & 8698 & 0 & 57000 \\
\hline & Machinery (Hours) & 95 & 146 & 2 & 940 \\
\hline & Labour (man-day) & 23 & 40 & 3 & 330 \\
\hline \multirow[t]{3}{*}{ Farmer's profile } & Age (years) & 54 & 9.6 & 27 & 78 \\
\hline & $\begin{array}{l}\text { Education level: NI ( } 2 \text { if the education level was up to primary, } 1 \\
\text { otherwise) }\end{array}$ & 1.32 & 0.47 & 1 & 2 \\
\hline & $\begin{array}{l}\text { Main Occupation ( } 1 \text { if the famers has agriculture as main } \\
\text { occupation, } 0 \text { otherwise) }\end{array}$ & 0.31 & 0.47 & 0 & 1 \\
\hline \multirow[t]{6}{*}{ Farms' specific factors } & Farm Size ( farm area in ha) & 140 & 247 & 6 & 2000 \\
\hline & Variety ( 1 if farmer uses selected seeds, 0 otherwise) & 0.53 & 0.5 & 0 & 1 \\
\hline & $\begin{array}{l}\text { Nitrogen application( } 1 \text { if farmer uses } 3 \text { times amonitrate, } 0 \\
\text { otherwise) }\end{array}$ & 0.58 & 0.5 & 0 & 1 \\
\hline & Herbicides ( 1 if farmer applies herbicides, 0 otherwise) & 0.48 & 0.5 & 0 & 1 \\
\hline & Pesticides (1if farmer applies pesticides, 0 otherwise) & 0.43 & 0.50 & 0 & 1 \\
\hline & Previous crops ( 1 if previous crops was leguminous, 0 otherwise) & 0.46 & 0.50 & 0 & 1 \\
\hline
\end{tabular}

Table 2 Frequency of distribution of PTE, SE, and OTE estimates

\section{1. Efficiency scores results}

The estimation of efficiency scores through DEA models was conducted using the DEAP (Data Envelopment Analysis Program) software. Distribution of PTE, SE and OTE of durum wheat farms considered in our sample are summarized in Table 2.

The analysis shows that the average OTE is about $58 \%$ under CRS assumption. This reflects that the current level of output can be achieved using $42 \%$ less inputs on average. OTE varies between a minimum of about $10 \%$ and a maximum of $100 \%$. We note that $54 \%$ of farms have OTE scores less than or equal to $50 \%$; about $18 \%$ of them are of an efficiency ranging between $50 \%$ and $75 \%$ and $29 \%$ of farms have an OTE strictly greater than $75 \%$. And about $42 \%$ of the farms have OTE scores greater than the mean. These results provide information on the heterogeneity of the farm's performances and the potential for increasing wheat production in the region of Zaghouan.

When adjusted for farm size, it's clear that many farms have high level of pure technical efficiency with an average of $73 \%$, and

\begin{tabular}{|lccc|}
\hline & PTE & SE & OTE \\
\hline Mean (\%) & 73 & 81 & 58 \\
\hline Min (\%) & 34 & 10 & 10 \\
\hline Max (\%) & 100 & 100 & 100 \\
\hline Std. Dev (\%). & 22 & 21 & 24 \\
\hline$>$ Mean (\%) & 50 & 63 & 42 \\
\hline OTE $\leq 25 \%$ & 0 & 1 & 2 \\
\hline $25<$ OTE $\leq 50 \%$ & 20 & 10 & 51 \\
\hline $50<$ OTE $\leq 75 \%$ & 30 & 20 & 18 \\
\hline OTE $>75 \%$ & 50 & 69 & 29 \\
\hline CRS $(\%)$ & & 13.3 & \\
\hline DRS (\%) & & 12.4 & \\
\hline IRS (\%) & & 74.3 & \\
\hline
\end{tabular}


$50 \%$ of farms have PTE greater than $75 \%$. The scale efficiency level of $81 \%$ indicates that the average farm is $19 \%$ scale inefficient. The low level of PTE compared to the SE level suggested that inefficiencies are mostly due to inefficient management practices since production can be improved by $27 \%$.

Results also revealed that $74.3 \%$ of farms are experiencing in increasing returns to scale; while 12.4 of them have decreasing returns to scale and only $13.3 \%$ are scale efficient. Therefore, the majority of farms can increase their production efficiency through increasing their input use. This confirms the major problem of wheat sector in Tunisia which is related to the small size of farms. More than $85 \%$ of wheat farms in Tunisia have an area lower than 20 ha (Ministry of Agriculture and Water Resources, 2010).

The calculated IRT and IATR are presented in table 3 . The results show the inputs reduction target, so none input is used at the optimal level. The result signifies that if the farmers were to operate efficiently (i.e. have zero inputs slacks), the present inputs level should be reduced about $24 \%, 27 \%, 34 \%, 38 \%, 51 \%, 26 \%$ and $43 \%$ respectively for area, seeds, nitrogen, DAP, treatment, machinery and labour. This means that the majority of farmers can achieve significant savings in inputs use if they would know how to improve the current production system exploitation. Wheat farmers in the study area are unaware of the recommended quantities of input to apply. Therefore, they generally depend on their experience to perform their production activities which results to inefficient use of inputs

The consequence of over utilization of inputs increases the production costs which results in low profit for farmers and ultimately low standard of living. Hence, farmers need some adjustments in their use of production inputs in order to keep operating on the frontier technology.

\subsection{Explaining efficiency}

An important issue of the efficiency analysis is not only to determine the efficiency levels but also to be able to explain its variation with reference to characteristics of the production units. One possible approach is to interpret the efficiency measures as a dependent variable that is determined by a set of production unit characteristics and practices. The results of the Tobit model estimation by Likelihood are shown in Table 4 .

We note that the likelihood ratio (LR) test is statistically significant at $1 \%$. Thus the model is mainly acceptable, and rejects a null hypothesis that all slope parameters are simultaneously zero set. All independent variables are with a positive sign indicating that they contribute to improve technical efficiency.

The tobit model indicates that the majority of exploratory variables have significant effects at the level of 5\%.

The estimation results obtained allow us to note that the following explanatory variables: age, education level, size, nitrogen application and pesticides are significant at the level of 5\% and the threshold of $10 \%$ for the rest of independents variables except the variety variable which is marginal significant with a t test of 1.55 .

The nitrogen use variable has the most important marginal effect on the technical efficiency with a coefficient of 0.14 indicating that when farmers apply nitrogen three times with sufficient quantity can improve their productivity by $14 \%$ other things being equal. The education level variable with a positive coefficient of 0.135 indicates that technical efficiency can be improved by $13.5 \%$ when farmers have achieved secondary or higher schooling. The positive relationship between the educational level of household head and technical efficiency can be supported by similar results reported in studies which have focused on the association between formal education and technical Efficiency. In general, more educated farmers are able to perceive and interpret and respond to new information and adopt improved technologies such as fertilizers, pesticides, and planting materials faster than their counterparts.

This implies that an increase in human capital will boost the productivity of farmers since they will be able to better allocate both family-supplied and purchased inputs and utilize the appropriate quantities of it while applying adequate techniques to get higher incomes. This is confirmed by the positive relationship

Table 3 Inputs targets, adjustments and IATR

\begin{tabular}{|lcccccrr|}
\hline Inputs & Area & Seeds & Nitrogen & DAP & Treatment & machinery & Labour \\
\hline Actual & 7524 & 12953 & 12844 & 7996 & 567176 & 9975 & 2380 \\
\hline Target & 5741 & 9421 & 8423 & 4973 & 280207 & 7364 & 1365 \\
\hline Radial Adjustments & -1629 & -2795 & -2740 & -1994 & -139551 & -2165 & -703 \\
\hline Slacks & -154 & -737 & -1681 & -1029 & -147418 & -446 & -312 \\
\hline IRT & -1783 & -3532 & -4421 & -3023 & -286969 & -2611 & -1015 \\
\hline Input Adjustment Target Ratios & $-24 \%$ & $-27 \%$ & $-34 \%$ & $-38 \%$ & $-51 \%$ & $-26 \%$ & $-43 \%$ \\
\hline
\end{tabular}


Table 4 Tobit estimation results of factors affecting efficiency scores

\begin{tabular}{|llll|} 
Variables & Coefficient & $\mathbf{t}$ & $\mathbf{P}>\mathbf{t}$ \\
\hline Age & 0.007 & 4.22 & 000 \\
\hline Education level & 0.135 & 2.51 & 0.014 \\
\hline Main occupation & 0.01 & 1.82 & 0.072 \\
\hline Farm Size & 0.001 & 2.28 & 0.025 \\
\hline Variety & 0.05 & 1.55 & 0.124 \\
\hline Nitrogen use & 0.14 & 3.93 & 000 \\
\hline Herbicides & 0.06 & 1.7 & 0.092 \\
\hline pesticides & 0.11 & 2.67 & 0.009 \\
\hline Previous crops & 0.06 & 1.81 & 0.074 \\
\hline Constant & -0.204 & -1.7 & 0.09 \\
\hline LR chi2 & 117.21 & & \\
\hline Prob> chi2 & 000 & & \\
\hline Log likelihood & 23.469 & & \\
\hline
\end{tabular}

between the age and the efficiency which indicates that the more farmers are experimented, the more they are efficient.

The technical package set including variety, nitrogen use, herbicides, pesticides and previous crops indicates significant positive effect of the package use on the farms efficiency. So farms can improve their performance by giving more interest to each of these variables.

The adoption of new agricultural technology is assumed to lead to higher growth in both the productivity and the production of food grains. Thus, farmers would be able to utilise the agricultural production factors at an optimal level alongside technical knowledge diffusion.

Finally, based on the empirical results, some suggestions and policy recommendations can be raised such as encouraging technological package and supporting the use of durum wheat varieties adapted to the region, setting up relevant training programs and improving extension services. All of these measures are needed in order to increase the efficiency of wheat production in Zaghouan.

\section{Conclusion}

During the last few years, the Tunisian wheat sector was characterized by an expanding gap between consumption and production. The need to improve efficiency of wheat at farms level has been accentuated because of the high level of wheat imports and the increasing importation bill in Tunisia. Overall technical, pure technical and scale efficiencies have been estimated for a sample of 105 wheat farmers in Zaghouan region (Central Tunisia) using Data Envelopment Analysis method. The factors, which influence the efficiency scores in rainy wheat production, have been also determined using a Tobit model.

The main results that can be retained from this analysis indicate the existence of low efficiency. The average OTE, PTE and SE efficiencies are $58 \%, 73 \%$ and $81 \%$ respectively, indicating that production efficiency can be improved by $42 \%$ without having to increase their volumes of inputs. The low level of PTE compared to the SE level suggested that inefficiencies are mostly due to inefficient management practices. Indeed, $74.3 \%$ of farms are experiencing in increasing returns to scale, while 12.4 of them have decreasing returns to scale and only $13.3 \%$ are scale efficient. The scale inefficiency can only be overcome by adopting new technology or new service production processes. By contrast, the technical inefficiency is a managerial problem, where more outputs are required for a given level of resources. In addition, findings show that none input is used at the optimal level. The result signifies that if the farmers were to operate efficiently (i.e. have zero inputs slacks), the present inputs level should be reduced by about $24 \%, 27 \%, 34 \%, 38 \%, 51 \%, 26 \%$ and $43 \%$ respectively for area, seeds, nitrogen, DAP, pesticides, machinery and labour. Hence, the farmers need some adjustments in their use of production inputs in order to operate on the frontier technology.

The paper investigated a number of factors associated with efficiency scores. Education level of farmers, farm size, main occupation, and technical package set including variety, nitrogen use, herbicides, pesticides and previous crops which are important determinants of efficiency which can be incorporated into the agricultural policy in Tunisia in order to raise the current level of productivity, food security and hence the sustainability development.

\section{References}

Banker RD, Chames A, Cooper WW (1984) Some models for estimating technical and scale efficiencies in data envelopment analysis. Management Science 30. 1078-1092.

Boussofiane A, Dyson RG, Thanassoulis E (1992) Applied data envelopment analysis. European Journal of Operation Research 52:1-15.

Charnes A, Cooper WW, Rhodes E (1978) Measuring the efficiency of decision making units. European Journal of Operational Research 2:429-441.

Chavas JP, Aliber M (1983) An Analysis of Economic Efficiency in Agriculture: A Nonparametric Approach. Journal of Agricultural and Resource Economics 18 : 1-16 
Coelli TJ (1995) Recent Development in Frontier Estimation and Efficiency Measurement. Austalian. Journal of Agricultural Economics 39: 219-245.

Coelli TJ (1996) A guide to DEAP Version 2.0: a data envelopment analysis (computer) program. Center for Efficiency and Productivity Analysis (CEPA) Working Paper 96/ 08. Department of Econometrics. University of New England, Armidale, Australia.

Cooper WW, Seiford LM, Tone K (2006) Introduction to DEA and its uses with DEA-Solver software and references. New York: Springer.

Cooper WW, Kumbhakar SC, Thrall RM, Yu XL (1995) DEA and Stochastic Frontier Analyses of the 1978 Chinese EconomicReforms. Socio-Economic Planning Sciences 29: 85-112

Dhungana BR, Nuthall PL, Nartea GV (2004) Measuring the Economic Inefficiency of Nepalese Rice Farms using Data Envelopment Analysis. The Australian Journal of Agricultural and Resource Economics 48 : 347-369.

Dinc M, Haynes KE, Stough RR, Yilmaz S (1998) Regional Universal Telecommunication Service Provisions in the US: Efficiency versus Penetration. Télécommunication Policy 22. 541-553.

Chemak F, Dhehibi B (2010) Efficacite technique des exploitations en irrigue: une approche parametrique versus non parametrique. New Medit 9: 32-41.

Chebil A, Frija A, Thabet C (2015) Economic efficiency measures and its determinants for irrigated wheat farms in Tunisia: a DEA approach. New medit 14:32-38

Chebil A, Frija A, Amri S (2014) Impact Assessment of Technology Change on Durum Wheat Productivity: A Cross Sectional Analysis in Central Semi-arid Tunisia. Journal of Agricultural Science and Technology B 4: 49-57.

Farrell MJ (1957) The Measurement of Productive Efficiency. Journal of Royal Statistical Society, ACXX 3:153-290.

FAO (Food Agriculture Organisation of the United Nations) (2014). FAO-STAT agriculture data. Available at htt://faostat.fao.org.

Fletschner DK, Zepeda L (2002) Efficiency of Small Landholders in Eastern Paraguay. Journal of Agricultural and Resource Economics 27 : 554-572.

Holden D (2004) Testing the normality assumption in the Tobit Model. Journal of Applied statistics 31:521-532.

Hu JL, Wang SC, Yeh FY (2006) Total-factor water efficiency of regions in China. Resources Policy 31 : 217-230.

Kumbhakar SC (1994) Efficiency Estimation in a Profit
Maximising Model using Flexible Production Function. Agricultural Economics 10: 143-152.

Laajimi A, Goychuk K, Meyers WH, Binfield J (2013) The Tunisian Wheat Market in the Context of World Price Volatility: A Stochastic Partial Equilibrium Approach. 133 EAAE seminar, Chania, Grece held on 14-16 June 2013.

Ministry of Agriculture and Water Resources (2010) Economic budget for the year 2011.Arab report. December 2010. 153 p. "(in French).

Naceur M, Sghaier M, Bachta MS (2010) Water use and technical efficiencies in private irrigated perimeters in Zeuss-Koutine Watershed, South-Eastern Tunisia. In: BALWOIS 2010 Conference, 25- 29 May, Ohrid, Republic of Macedonia.

Olesen OB, Petersen NC, Lovell CAK (1996) "Editor's Introduction.” Journal of Production Analysis 7:87-98.

ONAGRI (Observatoire National de l' Agriculture) (2015) Indicateur sur la céréaliculture. http://www.onagri.nat.tn/indicateurs?id=1

Sharma KR, Leung P, Zaleski HM (1997) Production Efficiency of the Swine Industry in Hawaii: Stochastic Frontier vs. Data Envelopment Analysis. Journal of Productivity Analysis 8 : 447459.

Sharma KR, Leung P, Zaleski HM (1999) Technical. Allocative and Economic Efficiencies in Swine Production in Hawaii: A Comparison of Parametric and Nonparametric Approaches. Agricultural Economics $20: 23-35$.

Speelman S, D’Haese M, Buysse J, D’Haese L (2008) A measure for the efficiency of water use and its determinants, a case study of small-scale irrigation schemes in North-West Province. South Africa. Agricultural Systems 98: 31-39.

Theodoridis AM, Psychoudakis A (2008) Efficiency Measurement in Greek Dairy Farms: Stochastic Frontier vs. Data Envelopment Analysis. International Journal of Economic Sciences and Applied Research 1 : 53-67.

Theodoridis AM, Anwar MA (2011) Comparison of DEA and SFA Methods: A Case Study of Farm Households in Bangladesh. The Journal of Developing Areas 45 :95-110.

Wadud A (2003) Technical. Allocative. and Economic Efficiency of Farms in Bangladesh: A Stochastic Frontier and DEA Approach. The Journal of Developing Areas 37 :109-126.

Wadud A, White B (2000) Farm Household Efficiency in Bangladesh: A Comparison of Stochastic Frontier and DEA Methods. Applied Economics $32: 1665-1673$.

Wu S, Prato T (2006) Cost Efficiency and Scope Economies of Crop and Livestock Farms in Missouri. Journal of Agricultural and Applied Economics 38 : 539-553. 